\title{
Rheological properties of natural fiber polymer composites
}

\begin{abstract}
Rheology is the study of how materials deform when a force is applied to them. These materials are mostly liquids or liquid-like materials. The applications discussed herein are concerned with polymer systems in the molten state. These materials are considered as visco-elastic. Rheology is an effective tool to better apprehend the quality control of raw materials, manufacturing processes/final product and predicting material performance. In particular, rheology is effective to better understanding the role that fillers have on the rheological properties of composites. In this paper, a short communication is rendered on the rheological properties of natural fiber polymer composites.
\end{abstract}

Keywords: visco elastic, rheology, natural fiber, polymer composites, optimization, rheometers
Volume I Issue 4 - 2017

\author{
Ogah Anselm Ogah \\ Department of Industrial Chemistry, Faculty of Science, Ebonyi \\ State University, Nigeria
}

\author{
Correspondence: Ogah Anselm Ogah, Department of \\ Industrial Chemistry, Faculty of Science, Ebonyi State University, \\ PMB 053, Abakaliki, Ebonyi State, Nigeria, \\ Email anselmogah@gmail.com
}

Received: August 23, 2017| Published: September 06, 2017
Abbreviations: MFI, flow index; WPCs, wood plastic composites; PE, polyethylene; PVC, polyvinylchloride; PP, polypropylene; PLA, polylactide; WF, wood flour; i-PP, isotactic polypropylene

\section{Introduction}

The rheological properties of filled polymer systems are not only determined by the polymer but also by the type of filler, its size, shape and amount. Another key factor is the interface that exists between filler and polymer. Thus, rheological properties are affected by this adhesion. Other additives, such as lubricants, are also added to formulations to alter flow properties. Understanding how fillers and additives affect the rheological properties of polymers is crucial in process optimization, trouble shooting and equipment design. To better understand the effects that fillers and additives have on rheological properties, rheometry must be employed. Rheometers are used to measure the effect of fillers on polymer systems. They can be divided into two categories: rotational and capillary types. The rheometers of interest include torque rheometer (capillary, extrusion type), parallel-plate (rotational), and melt flow indexer (capillary). Four types of rheological experiments can be performed utilizing parallel-plate or rotational rheometer: (i) strain sweep, (ii) frequency sweep, (iii) temperature sweep and (iv) steady shear sweep. The independent variables could be chosen as wood content, melt flow index (MFI) of polymer, melt temperature, frequency or shear rate, the gap between the plates, and strain percentage.

Recent years have witnessed the increasing awareness of environmental protection worldwide. Wood plastic composites (WPCs $)^{2-4}$ are by far regarded as an environmentally-friendly approach of using waste wood and recycled plastic materials, including polyethylene (PE), polyvinylchloride (PVC), polypropylene (PP), polylactide (PLA), and so forth. As compared to the solid wood, WPCs need substantially low maintenance cost. Due to the combination of characteristics from both plastics and wood, WPCs have gained wide application in our daily life ever since 1990s. ${ }^{5}$ WPCs also have their disadvantages, such as easy absorption of moisture, flammability, thermal expansion, creep (time-dependent deformation), as well as the difficult application of paint, etc. Those shortcomings limit the application of WPC to an extent. For facilitating the optimal processing conditions as well as improving the performance of the end products, additives (e.g., coupling agents, lubricants, mineral fillers, heat or UV stabilizers, colorants, etc.) are usually utilized, for instance, coupling agent is an efficient way to enhance the compatibility between hydrophilic wood and hydrophobic plastic. ${ }^{6,7}$ However, addition of the chemical additives will inevitably lead to the complication of the WPC formulae. As a result, making one property stand out is always coupled with reducing another property, since the physical and mechanical properties of WPCs depend heavily on the interactions between wood and thermoplastic materials..$^{8-10}$

Adhikary et al. ${ }^{11}$ argued that the performance of wood-plasticcomposites could be optimized by adjusting the processing parameters and material formulations. An appropriate combination of HDPE, WF, lubricants, and maleic anhydride-g-polyethylene contents provided the benefits of lower shear viscosity (favorable to processing) while maintaining the mechanical properties and surface smoothness of the extruded WPC profiles. As it is well known, the materials' processing behaviors substantially affect the end-use properties. However, the investigation on WPCs' rheological properties which is practically significant to understand the flow characteristics as well as the molecular structure involved in the WPCs, is still inadequate. Considering the limited influence exerted on the melt structure, rheological data would give a good insight into the optimization of the processing variables of WPCs.

In spite of rapid growth of using wood plastic composites in automotive and other industries, especially at North America, the published information in the field of rheology of WPC is scanty. Rheology can interpret degree of dispersion of wood fiber, behavior of interfacial region, and polymer-wood fiber affinity and has a vital role in processing of these composites. ${ }^{12,13}$ Both capillary and oscillatory rheometers have been reported to generate rheological data for WPC. Because of migration (from wall to center) and breaking of wood fibers at high shear rates in capillary rheometer, using of dynamic oscillatory technique is recommended. 
Maiti et al. ${ }^{14}$ studied the effect of wood flour (WF) concentration on the rheological behavior of isotactic polypropylene (i-PP)/wood composite in capillary rheometer. They showed that the shear stress rate variation obeys a power law equation, and the composite exhibited shear thinning property with increasing filler content. Harper et al. ${ }^{15}$ studied the influence of lubricant on rheological behavior of WF-filled polypropylene (PP) composite. Their results showed that the addition of internal lubricant is effective in reducing apparent viscosity which tends to increase with adding of WP. The rheological behavior of HDPE/WF composite under the steady shear and extensional flow has been studied by Li et al. ${ }^{16}$ They found that the extensional viscosity do not get affected by wood content significantly. They also analyzed the wall slip of composite and reported that the rate of this phenomenon is influenced by wood content. ${ }^{17}$

Ogah et al. ${ }^{18}$ investigated the effect of high fiber content ( 65 wt.\%) on the rheological properties of composites made using HDPE and corncob, rice hull, flax shive and walnut shell flour. Results indicated increase in complex viscosity, loss and storage moduli with a decrease in damping factor. Also, Shumigin et al. ${ }^{19}$ studied the effect of low amounts of cellulose on the rheological properties of composites of PLA and LDPE. They observed that the composites exhibited improvement in the storage and loss moduli compared with that of matrix polymers.

\section{Result and discussion}

\section{Materials}

The polymeric matrix used was HDPE (Ineos ${ }^{\circledR} \mathrm{HP} 54-60$ ) with density of $0.95 \mathrm{~g} / \mathrm{cm}^{3}$, MFI of $0.35 \mathrm{~g} / 10 \mathrm{~min}$. The corncob, rice hull, flax shive and walnut shell fibers of 60-100 mesh were used as received from the manufacturers.

\section{Rheological analysis}

Measurements of rheological properties were performed using a discovery (HR-2) hybrid parallel-plate rheometer (TA Instruments). Tests were carried out in steady rate at $170^{\circ} \mathrm{C}$ for $10 \mathrm{~min}$. Tests were done in a range of rates from 0.1 to $100 \mathrm{rad} / \mathrm{s}$. For all experiments, the strain amplitude was maintained constant at $2 \%$.

\section{Conclusion}

This study as shown that natural fibers can be processed with thermoplastic polymers as matrix materials for natural fiber composites. It has been found that fiber type, content, particle size and shape influences the rheological properties of the final composites.

\section{Acknowledgements}

I wish to acknowledge the Composite Materials and Engineering Center, Washington State University, Pullman, WA, USA for granting me the opportunity to do data analysis of my $\mathrm{PhD}$, as a visiting scholar.

\section{Conflicts of interest}

The author declares no conflict of interest.

\section{References}

1. Mezger TG. Rheology Handbook. 2nd ed. Harnover, USA: Vincentz Network; 2006.

2. Kumar V, Tyagi L, Sinha S. Wood flour reinforced plastic composites: a review. Research Chemical Engineering. 2011;27(5-6):253-264.
3. Buyuksari U, Ayrilnis N, Akbulut T. Compressed wood as source of reinforcing filler for thermoplastic composites. Journal of Applied Polymer Science. 2012;123(3):1740-1745.

4. Agnantopoulou E, Tserki V, Marras S. Development of biodegradable composites based on wood flour and thermoplastic starch, journal of applied polymer Science. 2012;126(S1):272-280.

5. Leao AL, Teixeira RM, Ferrao PC. Production of reinforced composites with natural fibers for industrial applications-extrusion and injection WPC. Journal of Molecular Crystallization of Liquid Crystals. 2008;484(1):523-532.

6. Wang Y, Cao JZ, Zhu LZ. Interfacial compatibility of wood flour/ polypropylene composites by stress relaxation method. journal of applied polymer Science. 2012;126(S1):E89-95.

7. Rodriguez Llamazares S, Zuniga A, Castano J. Comparative study of maleated polypropylene as a coupling agent for recycled low density polyethylene/wood flour composites. journal of applied polymer Science. 2011;122(3):1731-1744.

8. Arino R, Boldizar A. Processing and mechanical properties of thermoplastic composites based on cellulose fibers and ethylene-acrylic acid copolymer. Journal of Polymer Engineering Science. 2012;52(9):19511957.

9. Petchwattana N, Covavisaruch S. Influences of modified chemical agents on foaming wood plastic composites prepared from poly (vinyl chloride) and rice hull. Journal Material Design. 2011;32(306-307):869-873.

10. Leu SY, Yang TH, Lo SF. Optimized material composition to improve the physical and mechanical properties of extruded wood-plastic composites. Journal of Construction and Building Materials. 2012;29:120 127.

11. Adhikary KB, Park CB, Islam MR. Effects of lubricant content on extrusion processing and mechanical properties of wood flour high density composites. Journal of Thermoplastic Composites. 2011;24(2):155171.

12. Guo R, Azaiez J, Bellehumeur C. Rheology of fiber filled polymer melts: role of fiber-fiber interactions and polymer-fiber coupling. Journal of Polymer Engineering and Science. 2005;45(3):385-399.

13. Sewda K, Maiti SN. Effect of bark flour on melt rheological behavior of high density polyethylene. Journal of Applied Polymer Science. 2012;123(4):2122-2130.

14. Maiti SN, Subbarao R, Ibrahim MD. Effect of wood fibers on the rheological properties of i-pp/wood fiber composites. Journal of Applied Polymer Science. 2004;91(1):644-650.

15. Harper D, Wolcott M. Interaction between coupling agents and lubricants in wood-polypropylene composites. Composites Part A. 2004;35:385-394.

16. Li TQ, Wolcott MP. Rheology of wood plastics melt part 1 capillary Rheometry of HDPE filled with maple. Journal of Polymer Engineering \& Science. 2005;45(4):549-559.

17. Li TQ, Wolcott MP. Rheology of wood plastics melts part 3 non-linear nature of the flow. Journal of Polymer Engineering \& Science. 2006;46(1):114-121.

18. Ogah AO, Afiukwa JN, Nduji AA. Characterization and comparison of rheological properties of agro fiber filled high density polyethylene biocomposites. Open Journal of Polymer Chemistry. 2014;4(1):12-19.

19. Shumigin D, Tarasova E, Krumme A, et al. Rheological and Mechanical Properties of Poly (lactic acid)/Cellulose and LDPE/Cellulose Composites. J Materials Science. 2011;17(1):32-37. 